\title{
The Representations of Palestinians Behavioral Attributes in Hollywood Movies from 2000 to 2014
}

\author{
SAED JUNEIDI \\ MOHD NIZAM OSMAN \\ MEGAT AL-IMRAN YASIN \\ ROSYA IZYANIE SHAMSHUDEEN \\ Universiti Putra Malaysia \\ MOHD NOR SHAHIZAN ALI \\ Universiti Kebangsaan Malaysia
}

\begin{abstract}
Since the period followed the September 11 in 2001 attack, and the second Palestinian uprising in 2000 , Hollywood has produced many movies representing the Arab. The representation was shown in certain positions and scenes in the movie to give a certain meaning. Further, most of these previous studies have studied the personality in Hollywood movies combined with Arab characters. However, this study seeks to explore the behavioural attributes of the Palestinian character represented in Hollywood feature movies from the year 2000 to 2014 in detailed analysis. A literature analysis reviewed Arab representations in Hollywood movies. The quantitative approach is adopted as well as the data has been collected by employing the quantitative content analysis through using a coding sheet. The sample selection of this study is total population sampling. The unit analysis is 71 scenes that include and involve Palestinian character(s) within the five Hollywood feature movies. This study has approved that after the second Palestinian uprising in 2000 and September 2001 attack, the Palestinian behavioural attributes began to change. Thus, the behavioural attributes of The Palestinian character have represented in more complexity than the previous representation. Additionally, this study has observed that, after the September attack, Hollywood has modified the Palestinian behavioural representation.
\end{abstract}

Keywords: Palestinian, stereotype, terrorism, Hollywood movies, Palestinian behavioural.

\section{INTRODUCTION}

Hollywood is the most reputed, attractive and well-known American entertainment industry; it attracts people of all languages, races, colour, age, and ethnicity. Further, it reaches out to more than 150 countries around the world attracting all kinds of people; young teenagers, adults, men and women whom all have accessed to feature movies at any time and any place, and it is the most effective teaching tool for the new generation, and is an American tool for disseminating feelings, attitudes, and experiences to the world (Shaheen, 2012a). Moreover, Hollywood's motion pictures may have the ability and power to affect the minds of its audiences to believe in specific thoughts, opinions, and take views according to what they perceive through the big screen. Therefore, scenes, images, and characters may be repeated in different feature movies in an intelligent manner (Shaheen, 2012a). Consequently, these motion pictures are considered to have a lasting impact and are constant factors in changing concepts and beliefs, as it creates and installs stereotypes in its viewers (Rosmawati et al., 2012). Unfortunately, Hollywood has played a significant role in creating and reinforcing Arab and Arab-Muslim stereotypes on the one hand and making them ashamed of their legacy and 
history on the other hand. It is prevalent in Hollywood that stereotypes are considered as the best way to describe a particular group of people and introduce them to a different audience (Ullah \& Shahzor, 2017). Moreover, reinforce meant of a certain stereotype of people makes others look at this group from one point of view, leading to strengthening the belief that all people in this category are acting in the same manner and have the same qualities. As a result, this portrayal becomes familiar to the public, and they, in turn, believe this is the only thing this group essentially does. In turn, the same characteristic is perceived in all people from the same group. So, these negative descriptions lead the public to form negative judgments of this particular group (Ullah \& Shahzor, 2017).

When Israel was created in 1948, the Arab representations and more particularly the Palestinians became associated with the meaning of the Arab as a historical construction. It leads to historical stories, and biblical was used to define the rights for Muslims and Arab especially in Palestine (Mcalister, 2005), Hollywood feature movies at that period support the claim that Palestine which they called Holy Land was historically connected to the West through Christian and Jewish. (Shaheen, 2012b). The first representation of Palestinian was in 1960, with the release of the Exodus 1960 feature movie. This kind of context grew in proliferated and popularity throughout the 1970s-1980s, Then it had increased into the more common Arab terrorist and violence genre. The increasing feature movie productions of these genres resulted in a clear reaction to the rising involvement of the U.S. in the PalestinianIsraeli conflict, and the increasing of desperate and violent attempts of the Palestinian resistance to garner international recognition of the Palestinians suffering (Nor, 2012). The feature movie context of the 1970s-1980s do not express Islamophobic emotion, nor the Palestinian Israeli conflict was not presented as a religious one. The feature movie's political nature is made clear, and the feature movies representations of the conflict are biased (Shaheen, 2012b).

With the release of the Exodus 1960 feature movie, the Western perception of the Arab and Palestinian began to be created on the big screen. Based on the increasing American intervention in Arab affairs, and Americans' biased coverage of the conflict, Hollywood feature movie representations of the Palestinian Israeli conflict expressed American perceptions of Palestinian and Arabs as anti-Semitic, and violently unreasonable, and the Palestinian- Israeli conflict was represented as a struggle between bad-Arab Palestinians good Jewish (Shaheen, 2012b). Hollywood filmmakers began to produce feature movies that are communicative, and based on American attitudes toward the Arab. However, the PalestinianIsraeli conflict makes constant use of hostile representations of violent Arabs. Many people in the world have grown up believing that, Palestinians are terrorists, yet Israelis are innocents. Moreover, Palestine is a country without people, given to a people without a country; according to what has been portrayed on the big screen (Elayan, 2005).

Moreover, One of the most significant events that happened in recent years was the war on the Gaza Strip in the year 2014, there was a new wave of violence in the Gaza Strip, the number of Palestinian civilians killed in the battle of 2014 was more than any other year since the occupation of the West Bank and Gaza Strip began in 1967 (Zonszein, 2015).

In short, Palestinians have been functioned within the Hollywood feature movies released until the year $\mathbf{2 0 0 0}$ with somewhat unbalanced roles, to misrepresent the Palestinian issue. There are several studies on the Arab stereotypes and Arab representations in Hollywood feature movies before September 11 such as (Shaheen, 2012b), and some others about the effect of September 11 on the Arab and Muslim representation in feature movies such as (Marger, 2003). However, after September 11 several films were produced by 
Hollywood which represented Arabs, some of these films are related either to the PalestinianIsraeli conflict or to Palestinian characters, which were shown in certain places in the feature movie to give a particular meaning. The previous studies have been published to investigate and understand the stereotypical image of Arabs and Muslims in Hollywood feature movies. Most of these studies have examined the stereotype of the Palestinian cause in Hollywood feature movies combined with Arabs and Muslims.

Based on the frequency of Hollywood production, the vast size of their audiences and finally the global reach of their feature movies; Hollywood feature movies show a significant field for the study of representations of Palestinian presented in Hollywood feature movies during 2000 to 2014, because they have an enormous influence in shaping attitudes and behaviours of their audiences

This study contributes to the feature movie studies and literature for the scholars who are concerning with the fields of a feature movie. Further, it can be an essential reference to understand the Palestinian stereotype in Hollywood cinema. Besides, and would seek to increase social awareness among people, a greater understanding hopefully guides people to think and analyse views, perceptions and ideas they hold based on what they see in feature movies, and they cannot judge other people or society based on feature movies accordingly.

Moreover, this study indicates the propagation of these images that distort perceptions of Palestinians as well as the lack of balance in Hollywood feature movies. The results of this study can also be beneficial for the media industry and Palestinian governing bodies of the feature movie field to take responsibility to support the Palestinian cinema and to provide the necessary means for the development and improvement of Palestinian cinema. The understanding of the usage patterns of methodological approach, data gathering procedures and types of content used in the previous studies may be beneficial for other researchers who would like to pursue their studies related to feature movie studies.

\section{Arab and Muslim Representation}

It is vital to analyse and study the beginning of Arab representation in the West, as discussed by Edward Said in his book (Said, 1979). In his book, he discussed the contribution of Orientalism in creating a difference between the West and the East, whereby the West dominated the East, and the East was identified as the West's "Other" and also East considered West as the source of its identity.

By the shifting of power from Great Britain to America after the year 1945, Said tracked the transfer of this image to American popular attitudes, media, and foreign policies towards the Arabs (Said, 1979). He mentioned that the representations of the East are relatively associated with the economic, military, and political strategies of the western world. However, he observed that there are no specific criteria for the growth of the negative image of the Arab in the western media, particularly in Western cinema.

However, Shaheen (2012b), in his documentary book Reel Bad Arabs, analysed the Arab stereotype carefully as shown in nine hundred Hollywood feature movies. He studied Arab representation history in Hollywood cinema, from the early beginning to the year 2000, and he indicated that Hollywood cinema stereotyped the Arab in a strange way that gives negative feelings. Shaheen emphasised that Hollywood has presented Arab as a pestilential threatening culture and people of others. According to Shaheen, in the history of Hollywood within cinema Arabs have been regarded as the most maligned group, which exceeded the 
negative stereotype of Native Americans, Blacks, Asians. Shaheen, and Said, both links Hollywood power of politics together. He stated that Hollywood representations and politics reinforce each other.

Hollywood's misrepresentations of Arabs and Muslims influence significantly the people's opinion and shape and reformulate the way that Western people perceive Muslims (Shaheen, 2003). He firmly believed that this negative stereotype could change in terms of world politics.

In his research Shaheen (2012), dissected the origin of this stereotype. He studied how and why it had begun and spread in Hollywood cinema. He also warned the effects of the isolation process of the American people asking about the thing that must be done to change the Hollywood representation of the Arab. Through his earliest research on American television, he stated the image of the Arab in Hollywood cinema is quite likely those in television depictions.

However, Hall's concern with the social and political dimensions of communication is apparent from the very beginning. The meaning of the images of the 11 September 2001 attack on the World Trade Center were transmitted to a global audience, seemed the American nation had become the tragic victim of a terrorist attack. The media coverage highlighted the sense of tragedy surrounding the event in showing the sadness and traumatised reaction of European and American people. However, and in contrast to these sad scenes of mourning, the Western media also showed footage of some Palestinian and Arab people celebrating the news. Media discourses shaped the encoding of the 11 September attacks on terrorism, violence, and Islam that had been spread in the West for a long time ago. What viewers saw that day was a selective combination of reporters narratives, carefully edited individual videos and eyewitness statements to produce a story. Media coverage of the 11 September attack worked to secure a preferred meaning of the attack as a terrorist attack on the civilised world. Terrorism and civilisation were encoded and decoded as common-sense terms within these discourses. Nevertheless, these labels are not innocent and carry the ideological imprint of the West dominant cultural order (Procter, 2004).

\section{The Early Hollywood Production}

The historical roots of the stereotyped representations of the Arabs and Muslims must be known to have a comprehensive knowledge and to understand the stereotyped representation of the Arabs and Muslims in Hollywood feature movies. The history must be analysed to understand how Hollywood created stereotype representations.

This category started in the earliest days of Hollywood feature movies until the time of the Cold War. A researcher Edwards (2001), has made a direct link between the shift in Hollywood at the end of the Cold War, and instead of Soviet Communism, the Arabs are playing the enemy role in Hollywood Cinema. In the imagination of many Westerns With the end of the Cold, War Arab took the place of Soviet communism as a new enemy of the Western. He concludes that Hollywood Orientalism designed the negative stereotype of the Arabs, and it is insidious and persistent.

Nowadays, the image of Arab image had poorly been blurred. The image of Arab had been shown in magic lantern shows of various crusades and epics, against the murdering infidel (Ghareeb, 1983). The researcher Mcalister, (2005), explained the role of orientalism in this time, and how it is very influential in creating different tools through which the American 
people have represented the Arab as the children's feature movies and books, and Arabs had been shown as a world of fantasy and funny.

Another researcher Higashi (1994) also agreed with Mcalister (2005) in terms that orientalism plays an essential and influential role in representing the Arabs. This image is highly supported by many media productions that had represented the Arabian fantasy. Jacobson (2001) and Leach (1993) found out that improving media production and consumption in the American economy required Conquering new markets. Many of these narratives had been shown on the big screen; such as Garden of Allah, which was produced in 1917 and 1927 as silent feature movies, it was about an English woman and an Arabian sheikh who had a sexual adventure in the Arab desert, which is the origin of the Arab life. Then the Arab image was known in cinema.

Since the early times, Hollywood productions have meant to show and to expose Arabs as others, and the Western people showed as the white people. (Arti, 2007) argued that, many feature movies produced by Hollywood showed Western men rescuing and helping the Eastern people from primitive barbarian Arab sheikhs. However, Abdo (2002) confirmed that Arab Female also had been stereotyped by Hollywood feature movies. He stated that Hollywood has stereotyped Arab males as evil, disgustingly sinister and following by their sexual desire, and Arabian females have stereotyped as being demonised and humiliated (Abdo, 2002). Shaheen (2012) also agreed with Abdo (2002), that Hollywood had paradoxically portrayed Arab females, either as shapeless Black driven by males or as a dancer leering out from diaphanous veils. Abdo (2002) confirmed that this negative representation of Arabs had complimented the Orientalism concepts, which is the main concept of postcolonial theory.

Also, Hollywood at an early period had another stereotyped image of Arab man, which is the representation of Arabian sheikh. Shaheen (2012) observed that Hollywood feature movie started to present the Arabian typical sheikh in a perverted image. The real value of Muslim sheikh as a religious leader or an older man of wisdom had been damaged through one hundred and sixty Hollywood feature movies which have portrayed the sheikh as the slovenly, immoral, killer, always intent on capturing blonde-haired, pale-faced women for their harems. And these images had been presented in Power of The Sultan 1907, The Fire and The Sword 1914, The Sheiks 1921, and The Sheik's Wife 1922. Said (1979) noted that Arab sheikhs showed in the early Hollywood feature movies as they move violently to marry Western women.

Moreover, Hollywood feature movies had mixed the Arab heritage with Islamic principles to destroy the Arab culture. As Shaheen (2012) noted, Hollywood filmmakers have shown an entire group of Arabs people with the same person. Most of the Hollywood feature movies that Shaheen analysed portrayed Arabs as, bastards, pigs, rats and devil-worshipers and show them as violent, vicious and dirty images.

They were showing Arabs in this negative image while American as a hero was the primary strategy of the American that is. This has confirmed the link between American politics and businesses, and both were working to achieve their economic goals (Mcalister, 2005). As Raines (1977) demonstrated, during this period, the American model of economic, political and cultural development was replicated, and this strategy used by the American government as a preparation for a military expansion. 
After September 11 Attack

According to Arti (2009), September 11 was the actual break between the Hollywood industry and the American government, which increased after the invasion of Iraq. As Arti (2009) argued that there are many Hollywood filmmakers, free-thinking, activist members who participated in the social movements against the American foreign policy, especially in the Middle East. George Clooney and Steven Spielberg are among these free thinkers, and they co-own production companies. Arab was portrayed with greater complexity in the feature movies produced after September 11 (Alaklook, Aziz, \& Ahmad, 2016). Arab has been seen as victims as well as perpetrators, and they began to be treated impartially. Arab has been portrayed as more enlightened, in the feature movie produced after September 11 (Alaklook, Aziz, \& Ahmad, 2018), but a measure of the negative stereotype remains. Hollywood has been still sending out a warning message about the growth of fundamentalism and showing violence as justified in terms of Islamic doctrine (Arti, 2009).

Based on Shaheen (2012b), the national security advisor of the American President Jiminy Carter noticed that, the American feature movies and Television dramas showing Arab as evil character with religious gestures, these feature movies presented in a way that reminiscent of Nazi anti-Semitic campaigns. Moreover, Al-Jenaibi (2010) argued that after September 11 the themes of Hollywood feature movies had involved the Arabs and Muslims with modified characters introducing them as hesitant and ambiguous, Arabs and Muslims have always been connected to any unfortunate event, and they are still identified terrorist groups (Siddiqi, 2018). This kind of representations strengthens the appeal of the narrative of Hollywood's productions to the public (Foody, 2018). It also reinforces the distorting image of the Arab and Muslim as the villain in many Hollywood feature movies. Shaheen (2012b) argued that the increasing use of Arabs as terrorist characters must encourage the researchers to do more researches to analyse the impact of September 11 in Hollywood feature movies to raise awareness in the mainstream American society and also across the world. This depiction created misconception and unfair labelling that perpetuated by the American public (Al-Jenaibi, 2013).

Additionally, Al-Jenaibi (2010) argued that the attack of September 11 could be considered as an opportunity for the Hollywood industry. The Arab representation in Hollywood feature movies could be regarded as convenient to Hollywood's taste for entertainment. September 11 attack created many materials and narratives to be presented between good and evil and in most of these, the Arab became the most likely candidate for the terrorist action out to harm America and the world (Foody, 2018). The filmmakers make them correctly, and unforgotten looks like Arab by sometimes wearing usual gowns and speaking the Arabic accent (Al-Jenaibi, 2010).

Marger (2003) argued that the Arab representation in Hollywood feature movies was attributed to the economic and political events that happened in the Middle East during the 1970s. Then the attack of September 11 has significantly reinforced the negative image upon the Arab as they are brute, sleazy, and abusers of women. Moreover, Hollywood filmmaking represents the Arab culture elaborately, as the Arab cannot control their deeds because they have no formal culture. Eid (2014) argued that the Arab association with September 11 implies that, the Arab has little to control these terrorist group in protecting the lives of their people. Arab represented as heartless, and always ready to kill and attack. There was an implicit suggestion that Arab groups make the mass killing of other people for self-interests. According to Halse (2013), Hollywood feature movies represent Arab as rich serial killers and terrorists who usually use expensive weapons in their fight with each other. 
From all periods of Hollywood representation of Arab and Muslims, the representation of Arab and Muslims in the Middle East by Hollywood industry and filmmakers was produced by multifaceted factors that created a kind of relationship between the American Government and policymakers as well as the stereotypical portrait within the Middle East. Hollywood production since the early period has extraordinarily reflected the strong relationship between Hollywood and the American Government in the Middle East. Said's Orientalism was strongly emphasised by the representation of Hollywood's stereotype of Arab and Muslim categorised into a set of characteristics used and identified by filmmakers and their audiences as "Others" (Kennedy, 2013). Those people were frequently categorised into two unequal halves; the Occident and the Orient, thus the first can be regarded as the verses of the second, and both sides in opposition to one another, a cognitive construction and Hollywood representation for the Middle East allows America power, through Hollywood representation, to control the Middle East and to be under American control.

In a summary, the period preceded the September 11 attack, Hollywood has produced many feature movies that represent Arabs whether totally as Arab characters or partially as the Palestinian-Israeli conflict or the Palestinian personality with some specific meanings and implications. The previous studies have been published to analyse the stereotypical image of Arabs and Muslims in Hollywood feature movies, and most of these studies have examined the Palestinian character and cause in Hollywood feature movies combined with Arabs and Muslims. These studies have not addressed the Palestinian issues and Palestinian characters represented in Hollywood feature movies in detailed analysis. Moreover, these studies have not analysed the impact of this stereotype on the Palestinian-Israeli conflict or the reasons for creating such a stereotype or analysing Israel's involvement in influencing Hollywood in producing a particular image of the Palestinians.

\section{Framing Use in the Feature Movie}

In feature movie studies framing refer to the section of scenes, views Coleman (2010). Feature movie is a pathway that guides people to the imagination world; it is part of mass media that combines different types of art. Feature movie presents the story, which exists in the real world by organising the elements of the story within the frame to create a new meaning. The music, lighting, characters, dialogue, the creative collective strategies make a feature movie enjoyable (Campbell, 2010).

It is essential to know the feature movie's elements or how it is organised to create meaning to understand the feature movie's purpose. Ruangnapakul, Yusof and Hamid, (2015) stated that feature movies must be analysed in terms of "how" instead of "what", and it could be done through examining the mise-en-scene. Mise-en-scene is defined as a French term that means "placing on stage" (Moura, 2014). Mise-en-scene refers to the composition shot or frame of a feature movie, which includes all the elements in the frame of the camera. It contains camera movement, camera angles, lens choices and composition, type of shot, character's position, lighting, makeup and music that could also be considered in the mise-enscene (Ruangnapakul et al., 2015).

The feature movie directors, as well as the production studios, are the main essential controller of feature movie production. They control all feature movie elements and content in the screenplay that create the audience perceptions as they want (Ruangnapakul et al., 2015). Type of camera movements or camera angle is critical for the filmmakers to show their cinematic ideas. Therefore, framing in feature movie can be used to analyse how the 
filmmaker expresses ideas in the feature movie's story to the people. Based on (Coleman, 2010), feature movie is a type of visual media that contain images, dialogue lighting and other more to create meaning. However, all of these elements of visual framing have a tremendously powerful influence on viewer perception and memory than text. However, framing theory in this research has been used as a guide for the research to give more understanding of the Palestinian representation used in Hollywood feature movies.

\section{METHODOLOGY}

This research used a quantitative framework as the main methodology. The researcher has collected the data by employing content analysis from various journals. From the total number of 442 articles, only $8 \%$ articles in communication journals, and $16 \%$ articles in journals of the feature movie studies have mentioned a theory or model in the research framework (Manganello \& Blake, 2010). Thus, framing theory has been used as a guideline in this research.

Content analysis is used to examine the latent content and manifest content. This method is performed through an organised coding of content to categories according to specific procedures from the codebook to answer the research questions (Keyton, 2006). Manifest content refers to the visible or countable components of the content. Meanwhile, latent content refers to the meaning behind the text or manifest content (Graneheim \& Lundman, 2004). Besides, content analysis can be used to analyse the form of features, which is how the message is delivered, and the substantive elements of the content (Schreier, 2012).

Population sampling was used to select the sample in this study. The researcher has analysed the entire population because the size of the population that has a particular set of scenes are typically minimal. Five feature movies have been analysed in this study with the two variables, release date from 2000 to 2014 and the box office total equal to or greater than $\$ 40,000,000$. The samplings of this study are five Hollywood feature movies which are; Spy game (2001), The Sum of All Fears (2002), Munich (2005), You Don't Miss With The Zuhan (2008), and Body of Lies (2008). The total duration of the five Hollywood feature movies is $655 \mathrm{~min}$. Table 1 shows the primary information of each movie selected in this study.

Table 1: Main Information of the Selected Feature movies

\begin{tabular}{lccccc}
\hline \multicolumn{1}{c}{ Feature movie } & Director & $\begin{array}{c}\text { Released } \\
\text { Year }\end{array}$ & Duration & $\begin{array}{c}\text { Frequency } \\
\text { of Scenes }\end{array}$ & $\begin{array}{c}\text { Box Office } \\
\text { Total (USD) }\end{array}$ \\
\hline $\begin{array}{l}\text { You Don't Mess } \\
\text { with the Zohan }\end{array}$ & Dennis Dugan & 2008 & $1 \mathrm{~h} 53 \mathrm{~min}$ & 44 & 100 million \\
$\begin{array}{l}\text { Munich } \\
\text { Spy game }\end{array}$ & $\begin{array}{c}\text { Steven Spielberg } \\
\text { Tony Scott }\end{array}$ & 2005 & $2 \mathrm{~h} 44 \mathrm{~min}$ & 16 & 47 million \\
$\begin{array}{l}\text { The Sum of All } \\
\text { Fears }\end{array}$ & Phil Alden Robinson & 2001 & $2 \mathrm{~h} 6 \mathrm{~min}$ & 5 & 62 million \\
Body of lies & Ridley Scott & 2008 & $2 \mathrm{~h} 4 \mathrm{~min}$ & 4 & 118 million \\
\hline
\end{tabular}

The highest number of scenes is Munich because the storyline of the movies is about Palestine meanwhile and the other movies show the Palestinian character in specific scenes representing different cases. You Don't Mess with the Zohan is an action-comedy feature movie, released in 2008 by Columbia Pictures studio. Zohan character is superhuman, and he is a very respected and most vital soldier in the Israeli army. However, Zohan has felt bored by the continuous fighting and secretly planned to move out to the United States and work as a hairdresser. Zohan mission is to kill a Palestinian terrorist group leader named Fatoush, who 
is represented as a superhuman and robust character. Zohan faked his death as part of a mission and moved to the United States.

However, Munich is a historical, drama, and political thriller feature movie. It was directed by Steven Spielberg and written by Tony Kushner and released by Universal studio, with a total duration of two hours and forty-four minutes. Based on Box Office Majo, the total gross profit is $\$ 130,358,911$. Munich was nominated for five Oscars. According to Yuri (2010), this movie is based on a book by George Jonas (Jonas, 2005). The story is about a group of Palestinians known as Black September, posing as athletes, infiltrate the athlete's village at the Summer Olympic Games in Munich to take Israeli athletes hostage. They request the release of illegally Palestinian prisoners in Israeli Jails as a ransom. They finally kill all the hostages because the Israeli government refuses to negotiate.

The unit analysis of this study is each scene that contains a Palestinian character(s) within the movie. The feature movie scene was defined as a division of the feature movie that presented continuous action in one place (Ramasubramanian, 2005). If any scene does not contain any Palestinian character(s) present, the scene is not considered for coding. This study focuses on the characteristics that are presented as Palestinian within the scene in which they are presented. However, the total of 77 scenes have been coded from five feature movies as follows; Spy game (9 scenes), Sum of All Fears (3 Scenes), Munich (24 scenes), You Don't Miss With The Zuhan (33 scenes) and Body of lies (4 scenes).

Then, the coding has been measured in statistics by using the IBM SPSS Statistical Version 22 software to identify the stereotypes of Palestinian presented in Hollywood feature movies. The research objectives have been explained by descriptive statistics such as frequencies and percentage.

The codebook was developed to include the research variables which was specified based on the literature to be related to the study. The content-coding sheet is adopted based on Dana (2009), who selected variables initially to study how 9/11 changed Hollywood's Middle Eastern characters. These variables were the attributes that the past literature found as primary components of image formation and stereotyping in terms of the study (MonkTurner et al., 2010a).

The third sector includes the behavioural attributes which are 1) creativity; to indicate if the character has a creative idea in a problem solving, decision-making or can exceed original idea, rule or motivation to determine how was the character in pursuing his or her needs and/or wants and altruism which indicate to what extent the character tend to put the needs of others above his or her own, 2) friendly; which indicate how close is the character with others, 3) sexual orientation; which indicates what kind of sexual orientation the character is, 4) sexual contact; suggest if there is any sexual contact with other character, smoking, drinking alcohol, 5) terrorism; which indicate the likeliness of the character if he/she plan or commit, assist someone else in committing, or help plan an attack on non-military civilians, 6) victimisation; which indicates how the character has been portrayed, mood which indicates the mood of the character if happy, neutral, angry, sad or other, emotion expression which indicate how the character express his/her emotion in response to an action, 7) brave; which indicate if this character considered as a brave person if he/she involved in a danger action, leader which indicate if the character is consider as a leader in front of the people, helpful which indicate how much this character offering help to the people, and 8) apologetic; which indicate if the character be sincere in apologising in an incident (Monk-Turner et al., 2010b). 


\section{RESULT AND DISCUSSION}

Table 2: The Total Statistics of the Behavioural Attributes

\begin{tabular}{lcccc}
\hline \multicolumn{1}{c}{$\begin{array}{c}\text { Behavioural } \\
\text { Attributes }\end{array}$} & \multicolumn{2}{c}{ Highest } \\
\hline Creativity & Not Creative & $67.6 \%$ & Creative & $4.2 \%$ \\
Friendly & Not friendly & $40.8 \%$ & Not Applicable & $22.5 \%$ \\
Sexual Orientation & Unable to determine & $77.5 \%$ & Heterosexual & $22.5 \%$ \\
Sexual Contact & No & $97.2 \%$ & Yes & $2.8 \%$ \\
Terrorism & Yes & $69.0 \%$ & No & $31.0 \%$ \\
Victimisation & Aggressor & $49.3 \%$ & Victim & $22.5 \%$ \\
Braveness & No & $47.9 \%$ & Yes & $16.9 \%$ \\
Apologetic & Not Applicable & 63.4 & Yes & 7.0 \\
\hline
\end{tabular}

Based on the creativity statistics, the Palestinian characters are represented negatively. Most of the Palestinian is not creative, even though only in three scenes over 71 scenes of the Palestinian character has been shown as creative. This result indicates that Palestinians are followers, foul, and they are not decision-makers. Moreover, 20 scenes have no situation of creativity, which means the Palestinian character but in a position to do nothing.

The creativity and number of scene or role played by the Palestinian character are related as much as the Palestinian character represented in scenes as different creativity. Feature movies that represent the Palestinian character in the minimum number of the scene such as Spy Game, The Sum of All Fears, and Body of Lies, showed only one creativity frame unlike other feature movies with a significant number of scenes such as You Don't Mess with the Zohan and Munich. On the other hand, the number of scenes is not related to the type of the creativity frame, for instance, the highest number of the creativity frame in You Don't Mess with the Zohan is not creative, which is the same result for The Sum of All Fears, and Body of Lies.

Based on the friendship statistics, the Palestinians are presented negatively as they are not friendly people. However, in these feature movies, most of the friendship scenes are between Palestinians and Israelis. So the results showed the Palestinian character is not a friendly person, and he is not able to have a friendship relation with other people.

These results showing the majority of scenes are unable to deliver the sexual contact of the Palestinian. It means there is no relationship between the Palestinian character shown in these feature movies. This part is related to the gender part, which is already mentioned earlier. Based on gender statistics, the Palestinian male character has represented in the highest number of scenes, and this clearly explains the result showed in this part which is the highest number is unable to determine the sexual orientation of the Palestinian character. The statistical result of each movie in this part also related to the result of each movie in the gender part. The Palestinian character's gender in all scenes of the Spy Game, the Sum of All Fears, and Body of Lies feature movies is male. Also, the Palestinian sexual orientation in all scenes of these feature movies is unable to determine.

Gender, sexual orientation, and sexual contact are related to each other. As the majority of the Palestinian character is male and unable to determine their sexual orientations, so it explains the result of the highest number of the scenes represent the Palestinian character having no sexual contacts. Moreover, the sexual contact of the character 
is related to the movie dialogue, and this result could indicate that the Palestinian character's social life is not represented in this feature movies.

One of the most critical issues of this statistic is to indicate the Palestinian terrorist representation. In these feature movies, the Palestinian characters are shown as a terrorist, fighting and killing innocent people. There is no scene representing the rote of the Palestinian issue. Moreover, there is almost high agreement among the feature movie filmmakers on the terrorism frame of the Palestinian character. The gap between the highest number and the lowest in most of the feature movies is high except in You Don't Mess with the Zohan. This could be related to the movie genre. As You Don't Mess with the Zohan movie's genre is a comedy, so this explains the terrorism frame result.

Based on this, the majority of Palestinians are aggressors. These images make the viewer hate the Palestinians and be afraid of them, and always support the other party because the viewers believe that Palestinians are the aggressors. Moreover, once the viewers are set to decide whom to support, they will support the victim against the aggressor who is Palestinian. However, almost all the feature movies represent the Palestinian character in different victimisation frame, and there is no agreement among the filmmakers on one victimisation frame. Still, the highest number of the victimisation frame of the Palestinian character is aggressor, but this is not the same result of each movie. In Munich and Spy Game movies, the Palestinian characters were represented in the victim frame and aggressor frame in the same number of scenes.

However, most Hollywood feature movies represent the Palestinian character in different braveness frame, and there is no agreement among the filmmakers on one frame. Still, the highest number of the braveness frame of the Palestinian character is not brave, but this is not the same result of each movie. In Munich, Spy Game, and Sum of All Fears movies, the Palestinian characters braveness were not applicable.

Moreover, the number of negative behaviour of the Palestinian character is more than positive behaviour. The Palestinian are not socialised people, and they are not living their life as usual as ordinary people, and they are making the life of other people difficult. This result will cause Western people to hate Palestinians, to dislike them, to against them, and do not support them. Moreover, Western people will stand with Israeli and will give their support to them.

The previous researches that compared the Arab and the West together with Israel such as (Boggs, 2017; Deger, 2011b; Eid, 2014; Khatib, 2006b; Meiloud, 2007; Shaheen, 2012a; Wilkins \& Downing, 2002) agreed that the Arab and Palestinian had always been shown as the others, the enemy, always been causing the threat, uncivilised, undeveloped, resort to violence, savagery, wealthy, and lacking in honour and morals. However, the current study has analysed the Palestinian characters in more details, and they have not been represented as $100 \%$ negative. The current study approved that, there is no agreement among the Hollywood filmmakers on the representation of the Palestinian characters. Data showed $67.6 \%$ of characters are not creative compared to $4.2 \%$ are creative, $40.8 \%$ are not friendly, and $36.6 \%$ are friendly in a specific feature movie such as Munich. Meanwhile, $62.5 \%$ are friendly, and $37.5 \%$ are not applicable in the Spy Game. The total percentage of braveness is $47.9 \%$ compared to $16.9 \%$, but in Munich, $43.8 \%$ are brave, and $56.2 \%$ are not applicable. For leadership; $21.1 \%$ have leadership, and $33.8 \%$ did not have leadership. But in the Munich feature movie; $37.5 \%$ are brave, and $12.5 \%$ are not brave. Also, the Palestinian character is shown as helpful and apologetic, with $91 \%$ wearing western attire, $78.9 \%$ showed normal 
groomed, 60.6\% living in the middle class, 21.1 speak fluent English, and $70.4 \%$ speak in normal voice intonation. So these all numbers approved that the Palestinian characters have been shown differently.

The Hollywood feature movies widely used Arab terrorism. Boggs \& Pollard, 2006; Shaheen (2003) agreed that in recent years the distorted image of Arabs had been raised. The terrorism representation was used in the Arab Israeli conflict. Also, Arti, 2007; Fries, (2005), claimed that Hollywood had represented the Palestinian and Arab as terrorists, threatening the whole world, dangerous, and a killer. Further, they have been characterised as an extension of the Nazi threat. Some other researcher such as Mcalister, (2005), has linked the terrorism and threat representation with the oil emergence in the Middle East.

Other researchers such as Al-Jenaibi (2010), Foody (2018), and Shaheen (2012b) confirmed that Arab had been widely represented as terrorist and Hollywood was the main tool. They claim that the increasing use of this representation encouraged further research to analyse the impact of September 11 because it could be considered as an opportunity for the Hollywood film industry to raise awareness.

However, in the terrorism representation, the current study has found different results and implications, even for some related attributes, in the Palestinian character has shown in $69 \%$ of the scenes as terrorist behaviour and $31 \%$ are not a terrorist.

On the other hand, the data in table 3 shows, these feature movies represent the majority of Palestinian characters as male. The acting roles in feature movies are given based on the actor's gender. Most actors are given the roles associated with the dominant role, while actresses are given the supporting roles. Based on Smith, Choueiti, Prescott, \& Pieper, (2012), male are always in the majority of the character. Additionally, in this study, Palestinian men have gotten major roles more than women.

Table 3: The Frequency and Percentage of Gender in Each Feature movie

\begin{tabular}{llll}
\hline Feature movie Title & Gender & Frequency & Per cent \\
\hline You Don't Mess with the Zohan & Male & 36 & 81.8 \\
& Female & 8 & 18.2 \\
Munich & Male & 15 & 93.8 \\
& Female & 1 & 6.2 \\
Spy game & Male & 5 & 100.0 \\
The Sum of All Fears & Male & 4 & 100.0 \\
Body of lies & Male & 2 & 100.0 \\
Total & & 71 & 100.0 \\
\hline
\end{tabular}

\section{CONCLUSION}

Arab and Palestinian have always been represented in Hollywood movies as others, the enemy, always been causing the threat, uncivilised, undeveloped, resort to violence, savagery, wealthy, and lacking in honour and morals. However, the current study has analysed the Palestinian characters in more details, and they have not been represented as $100 \%$ negative.

This study has addressed the Palestinian issues and Palestinian behaviour represented in Hollywood feature movies. It has approved that after September 11 in 2001 and the Palestinian uprising in 2000, the behaviour of the Arab including the Palestinian character began to change. These events acted as a catalyst that stimulated more researches. As a result, the Palestinian character's behaviour was represented in more complexity than the previous representation. Also, this study has approved that, after these two events, 
Hollywood has modified the representation of Palestinian behaviour because there was no agreement on one negative frame of the Palestinian representation among the filmmakers.

However, this study could be used to understand the new policy of the Hollywood industry of representing the Palestinians. It could help the Palestinian Authority to increase the social awareness about the importance of movies, and it also could be used as a tool to build up the networking with the Hollywood industry to change the Palestinian representation. It also helps the Palestinian filmmakers to create a positive Palestinian representation in their movies.

\section{BIODATA}

Saed Juneidi is a PhD student at the Faculty of Communication and Modern Language, Universiti Putra Malaysia. Email: sdjuneidi@gmail.com

Mohd Nizam Osman is an Associate Professor, at the Faculty of Communication and Modern Language, Universiti Putra Malaysia. Email: mo_nizam@upm.edu.my

Megat Al-Imran Yasin is a lecturer at the Faculty of Communication and Modern Language, Universiti Putra Malaysia. Email: megat@upm.edu.my

Rosya Izyanie Shamshudeen is a lecturer at the Faculty of Communication and Modern Language, Universiti Putra Malaysia. Email: rosya@upm.edu.my

Mohd Nor Shahizan Ali is an Associate Professor at the Centre of Research in Media and Communication, Universiti Kebangsaan Malaysia. Email: shahizan@ukm.edu.my 


\section{REFERENCES}

Abdo, D. (2002). Uncovering the harem in the classroom: Tania Kamal-Eldin's" covered: The hejab in Cairo, Egypt" and" Hollywood Harems" within the context of a course on Arab women writers. Women's Studies Quarterly, 30(1/2), 227-238.

Alaklook, H., Aziz, J., \& Ahmad, F. (2016). Exploitation and new orientalism in Sam Kadi's the citizen. Jurnal Komunikasi: Malaysian Journal of Communication, 32(2).

Alaklook, H., Aziz, J., \& Ahmad, F. (2018). Ambivalence and sympathy: New Orientalism and the Arab characters in Ridley Scott's body of lies. e-Bangi, 13(5).

Al-Jenaibi, B. (2010). The competition between Al-Jazeera's Arab news diversity and US channels: Content analysis of the Iraq War. Canadian Social Science, 6(4), 81.

Al-Jenaibi, B. (2013). Satisfying public relations: The promise of social media in the UAE. International Journal of E-Adoption (IJEA), 5(1), 1-16.

Arti, S. (2009). Continuity and change in Hollywood representations of the Middle East after September 11th [Doctoral dissertation, Loughborough University, United Kingdom]. https://hdl.handle.net/2134/16858

Boggs, C. (2017). The Hollywood war machine: US militarism and popular culture. UK: Routledge.

Campbell, A. (2010). Imagining the 'war on terror': Fiction, film, and framing. In K. Hayward \&, M. Presdee (Eds.), Imagining the 'war on terror.' Framing Crime: Cultural criminology and the image (Chap. 7). Taylor \& Francis Group.

Coleman, R. (2010). Framing the pictures in our heads: Exploring the framing and agendasetting effects of visual images. In P. D'Angelo \& J. A. Kuypers (Eds.), Doing news framing analysis: Empirical and theoretical perspectives (Chap. 10, pp. 233-261). Taylor \& Francis Group.

Dana, M. (2009). Big-screen aftershock: How 9/11 changed Hollywood's Middle Eastern characters. Rochester Institute of Technology.

Deger, D. (2011a). The relation between Hollywood and the new threat perception of the USA after the end of the cold war from the perspective of postmodernism. CINEJ Cinema Journal, 1, 159-169.

Edwards, B. T. (2001). Yankee Pashas and buried women: Containing abundance in 1950s Hollywood orientalism. Film \& History: An Interdisciplinary Journal of Film and Television Studies, 31(2), 13-24.

Eid, M. (2014). Perceptions about Muslims in Western societies. In M. Eid \& K. H. Karim (Eds.), Re-imagining the other: Culture, media, and Western-Muslim intersections (pp. 99119). Springer.

Elayan, Y. (2005). Stereotypes of Arab and Arab-Americans presented in Hollywood feature movies released from 1994 to 2000. East Tennessee State University.

Foody, K. M. (2018). Muslims in the American media: From texts to affects. Journal of Islamic Studies, 29(2), 230-251.

Fries, J. C. (2005). Foes on film: The evolution of Hollywood portrayals of Soviets and Middle Easterners, 1980-2001 [Doctor of philosophy dissertation, College of Arts and Sciences of Ohio University]. ProQuest.

Ghareeb, E. (1983). Split vision: The portrayal of Arabs in the American media. Middle East Policy Council.

Graneheim, U. H., \& Lundman, B. (2004). Qualitative content analysis in nursing research: Concepts, procedures and measures to achieve trustworthiness. Nurse Education Today, 2, 105-112. 
Halse, R. (2013). Negotiating boundaries between us and them: Ethnic Norwegians and Norwegian Muslims speak out about the 'next door neighbour terrorist' in 24. Nordicom Review, 33(1), 37-52.

Higashi, S. (1994). Cecil B. DeMille and American culture: The silent era. University of California Press.

Jacobson, M. F. (2001). Barbarian virtues: The United States encounters foreign peoples at home and abroad, 1876-1917. Macmillan.

Jonas, G. (2005). Vengeance: The true story of an Israeli counter-terrorist team. Simon and Schuster.

Kennedy, V. (2013). Edward Said: A critical introduction. John Wiley \& Sons.

Keyton, J. (2006). Communication research: Asking questions, finding answers. McGraw-Hill.

Khatib, L. (2006b). Filming the Modern Middle East: Politics in the cinemas of Hollywood and the Arab world (Vol. 57). IB Tauris.

Leach, W. (1993). Land of Desire: Merchants, power, and the rise of a new American culture. Pantheon Books.

Manganello, J., \& Blake, N. (2010). A study of quantitative content analysis of health messages in US media from 1985 to 2005. Health Communication, 25(5), 387-396.

Marger, M. (2003). Race and ethnic relations: American and global perspectives. Wadsworth/Thomson Learning.

McAlister, M. (2005). Epic encounters: Culture, media, and US interests in the Middle East since 1945 (Vol. 6). University of California Press.

Monk-Turner, E., Heiserman, M., Johnson, C., Cotton, V., \& Jackson, M. (2010b). The portrayal of racial minorities on prime time television: A replication of the Mastro and Greenberg study a decade later. Studies in Popular Culture, 32(2), 101-114.

Nor, M. R. M. (2012). The role of the Zionist movement towards the creation of the state of Israel. International Journal of West Asian Studies, 4(2).

Procter, J. (2004). Stuart Hall. Routledge.

Raines, H. (1977). My soul is rested: Movement days in the deep south remembered. Penguin Group USA.

Ramasubramanian, S. (2005). A content analysis of the portrayal of India in films produced in the West. The Howard Journal of Communications, 16(4), 243-265.

Rosmawati Mohamad Rasit, Md Salleh Hassan, Mohd Nizam Osman \& Muhamad Sham Shahkat Ali. (2012). Relationship of viewing Islamic based films with pro-social personality among the teenaged audience. Jurnal Komunikasi: Malaysian Journal of Communication, 28(1).

Ruangnapakul, N., Yusof, N., \& Hamid, N. A. (2015). Violence against a woman in selected Thai films: A perspective. History, 5(16), 120-127.

Said, E. (1979). Orientalism 1978. Vintage Books.

Said, E. W. (2008). Covering Islam: How the media and the experts determine how we see the rest of the world (Fully revised edition). Random House.

Schreier, M. (2012). Qualitative content analysis in practice. Sage.

Shaheen, J. (2012b). Reel bad Arabs: How Hollywood vilifies a people. Interlink Publishing.

Shaheen, J. G. (2003). Reel bad Arabs: How Hollywood vilifies a people. The Annals of the American Academy of Political and Social Science, 588(1), 171-193.

Siddiqi, M. A. (2018). Terrorism: A cross-cultural comparative study of seven newspapers from around the world. Jurnal Komunikasi: Malaysian Journal of Communication, 19. 
Ullah, I., \& Shahzor, K. (2017). Cultural (mis) appropriation, ideological essentialism and language: Analysis of stereotyping in Hollywood feature movie. International Journal of English Linguistics, 7(6), 171.

Yuri, O. (2010). Applied mass communication theory: A guide for media practitioners, Jack Rosenberry and Lauren A. Vicker (2009). International Journal of Media \& Cultural Politics, 6(1), 118-120.

Zonszein, M. (2015). Israel killed more Palestinians in 2014 than in any other year since 1967. The Guardian. 